\title{
EFFECT OF HIP ADDUCTORS ON BASKETBALL PLAYERS BALANCE
}

\section{Rumiana Tasheva ${ }^{1}$, Georgi Mitrev ${ }^{2}$}

${ }^{1}$ National Sports Academy ,,Vassil Levski”, Sofia, Bulgaria

${ }^{2}$ Basketball Club „Rilski Sportist”, Samokov, Bulgaria

\begin{abstract}
The functional evaluation of athletes is the sports physiotherapist's initial opportunity to identify dysfunctions and muscle imbalance.

The aim of this study is to investigate the correlation between basketball players'shortening hip adductors with Patrick's Test and their balance and coordination with the Shark Skill Test.

Methods: We tested 65 healthy active basketball players in Basketball Club "Rilski sportist" Samokov and the National Bulgarian Basketball Team. The athletes were divided into 2 groups: 22 players in the first Control Group with average 20.9 years and 21 youth players in the second Group with average 15.6 years. They were observed voluntarily in 2016.

The 2 tests were applied at least 12 hours after the training. The shortness of hip adductors was assessed with Patrick's Test and balance and coordination skills - with Shark Skill Test.

Results: The results from the Shark Skill Test on the left and on the right lower limb demonstrated statistically significant better time and fewer mistakes among $1 G$ basketball players (average 20.9 years) with shorter left and right adductors than these with normal adductors' elasticity. In contrast, there were no statistically significant differences among the youth athletes.

Conclusion: Summarizing the results, it is clear that the basketball play causes the shortening of the hip adductors of men and teenagers. In this aspect, it is important that the asymmetry of the adductor elasticity in both groups does not lead to statistically significant differences in the duration and mistakes during performance of the Shark skill test.

In our opinion, it is necessary to expand the study by applying physiotherapy for the shortened hip adductors and track changes in the implementation of the Shark Skill Test before and after treatment.
\end{abstract}

Key words: basketball players, Patrick's Test, Shark skill test

\section{INTRODUCTION}

The functional evaluation of athletes is the sports physiotherapist's initial opportunity to identify dysfunctions and muscle imbalance. It is not a standardized test, but one geared toward improving athletic performance and preventing injuries. Basketball is a dynamic athletic game requiring specific technical skills and complex activity of motor abilities. In fact, high level of intensity, sudden stops with twisting movements and jumping often cause muscle dysfunction and this is one of the most important risk factors leading to in- jures. Tissue damage is almost always a result from dysfunction of the affected body part, and this is especially true of the lower limbs of basketball players. One of the most important muscle groups is that of hip adductors because of their role in stabilization and control of the pelvis, and the position of the innominate bone, especially while walking. The hip adductors can contribute to bilateral stability even in the absence of adequate hip abductor function (Gluck\&Liebenson, 1997). These muscles are very prone to cramps and shortening when they are stressed. The question is: 
Are the hip adductors shortened in basketball players and whether this causes difficulties in the implementation of the special balance test?

The aim of this study is to investigate the correlation between basketball players' shortening hip adductors with Patrick's Test and balance and coordination with the Shark Skill Test.

\section{METHODS}

The research was done among 65 healthy active basketball players in Basketball Club "Rilski sportist" - Samokov and the National Bulgarian Basketball Team. The athletes were divided into 2 groups: 22 players in the first Group (1G) with average 20.9 years and 21 youth players in the second Group $(2 \mathrm{G})$ with average 15.6 years. They were observed voluntarily in 2016.

The 2 tests were applied at least 12 hours after the training. The shortness of hip adductors was assessed with Patrick's Test in initial supine position with unilateral hip, knee and ankle flexion, and the foot against the contralateral knee (Levit, 1981). The assessment of the adductors involved passive hip abduction with contralateral stabilization on the pelvis (Figure 1).

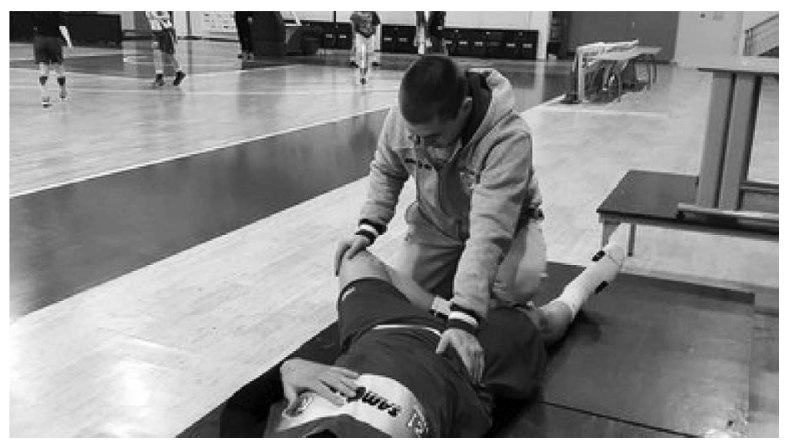

Figure 1. Patrick's Test

The distance from the knee to the support surface was measured in $\mathrm{cm}$. (Figure 2).

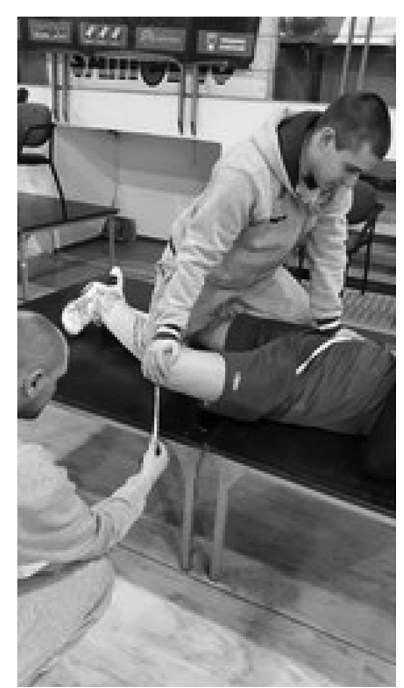

Figure 2. Patrick's Test Measurement

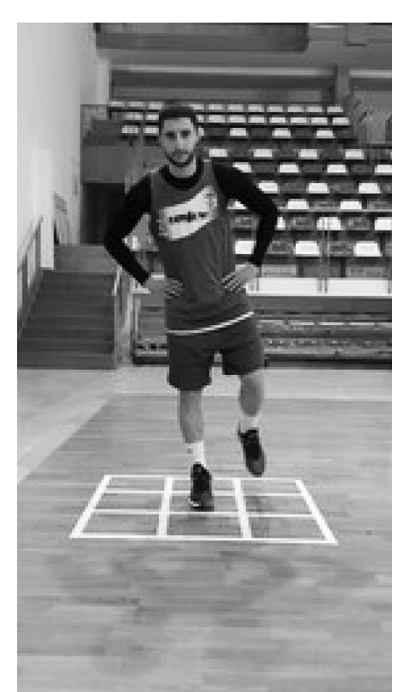

Figure 3. Shark Skill Test

For balance and coordination skills we used square to the each peripheral one with the hands Shark Skill Test in 90/90 cm square divided into 9 smaller numbered squares (Gatz, 2009). The athletes jumped on one leg from the middle on hips (Figure 3). For the right lower limb, the test was performed in a clockwise direction and for the left one in the opposite direction. 
The execution time and mistakes were recorded. The mistakes included: missing the middle or the other square, contact with the other leg, or movements with the upper limbs.

\section{RESULTS}

For the analysis of the results we used the program SPSS IBM. For the attached correlation analysis for hypothesis testing we used the t-criterion of Student for independent samples, and we also calculated Cohen's distinction of establishing the relevance of the difference in values (Damianova \& Gigova, 2000; Damianova \& Gigova, 2002).

Table 1. Results of $1 G$ 's Shark skill test in norm and shortened adductors of the left lower limb

\begin{tabular}{|c|c|c|c|c|c|c|c|c|c|c|}
\hline \multirow{2}{*}{ Shark skill test } & \multicolumn{3}{|c|}{ Norm add } & \multicolumn{3}{|c|}{ Shortened add } & \multirow{2}{*}{ d } & \multirow{2}{*}{$\begin{array}{c}\text { Cohen's } \\
\text { d }\end{array}$} & \multirow{2}{*}{$\mathrm{t}$} & \multirow{2}{*}{$P(t)$} \\
\hline & $\mathrm{n}$ & $\bar{X} 1$ & S1 & $\mathrm{n}$ & $\bar{X} 2$ & $\mathrm{~S} 2$ & & & & \\
\hline Left time & 3 & 5.93 & 0.35 & 19 & 4.62 & 0.66 & 1.3 & 0.778 & 3.30 & 100 \\
\hline Left mistakes & 3 & 2 & 1 & 19 & 0.7 & 0.87 & 1.2 & 0.570 & 2.30 & 97 \\
\hline Right time & 3 & 6.37 & 0.6 & 19 & 4.74 & 0.71 & 1.6 & 0.778 & 3.71 & 100 \\
\hline Right mistakes & 3 & 2.3 & 2.08 & 19 & 1.1 & 0.94 & 1.2 & 0.348 & 1.01 & 91 \\
\hline
\end{tabular}

Note: Critical value of the $t$-criterion of Student for independent samples at $d=n 1+n 2-2=20$ and a $=0.05$ equals 2.09 ; add -adductors.

Table 1 shows the correlation in $1 \mathrm{G}$ between Test for the left hip adductors and Shark Skill Test on the left lower limb in:

- shortened adductors: time - $4.62 \mathrm{sec}$; mistakes in the performance -0.7 errors;

- without shortening adductors: time -5.93 sec; mistakes in the performance - 2 errors;

- statistically significant difference in time $-1.3 \mathrm{sec}(t=3.3 ; \mathrm{P}(\mathrm{t})=100 \%)$;

- statistically significant difference in mistakes -1.2 errors $(t=2.30 ; \mathrm{P}(\mathrm{t})=97 \%$.);

- high practical importance Cohen's: time $d=.778$; mistakes $-d=.570$.
The correlation in $1 \mathrm{G}$ between Test for the left hip adductors and Shark Skill Test on the right lower limb is (Table 1):

- shortened adductors - $4.74 \mathrm{sec}$; mistakes in the performance - 1.1 errors;

- without shortening adductors - $6.37 \mathrm{sec}$; mistakes in the performance -2.3 errors;

- statistically significant difference in time $-1.6 \sec (t=3.71 ; \mathrm{P}(\mathrm{t})=100 \%)$;

- statistically significant difference in mistakes -1.2 errors $(t=1.01 ; \mathrm{P}(\mathrm{t})=91 \%$.);

- high practical importance Cohen's: time $d=.778$; mistakes $-d=.348$.

Table 2. Results of 2G's Shark skill test in norm and shortened adductors of the left lower limb

\begin{tabular}{|c|c|c|c|c|c|c|c|c|c|c|}
\hline \multirow{2}{*}{ Shark skill test } & \multicolumn{3}{|c|}{ Norm add } & \multicolumn{3}{|c|}{ Shortened add } & \multirow{2}{*}{ d } & \multirow{2}{*}{$\begin{array}{c}\text { Cohen's } \\
\text { d }\end{array}$} & \multirow{2}{*}{$\mathrm{t}$} & \multirow{2}{*}{$P(t)$} \\
\hline & $\mathrm{n}$ & $\bar{X} 1$ & $\mathrm{~S} 1$ & $\mathrm{n}$ & $\bar{X} 2$ & $\mathrm{~S} 2$ & & & & \\
\hline Left time & 4 & 6.93 & 1.42 & 17 & 6.93 & 1.56 & 0.00 & 0.000 & 0.01 & 1 \\
\hline Left mistakes & 4 & 3 & 1.41 & 17 & 2.2 & 1.6 & 0.8 & 0.256 & 0.95 & 74 \\
\hline Right time & 4 & 6.95 & 2.2 & 17 & 6.54 & 1.5 & 0.4 & 0.108 & 0.45 & 34 \\
\hline Right mistakes & 4 & 2.3 & 2.1 & 17 & 2 & 1.37 & 0.3 & 0.084 & 0.3 & 23 \\
\hline
\end{tabular}

Note: Critical value of the $t$-criterion of Student for independent samples at $d=n 1+n 2-2=19$ and a $=0.05$ equals 2.09; add-adductors.

Table 2 shows the correlation in $2 \mathrm{G}$ of the teenagers between Test for the left hip adductors and Shark Skill Test on the left lower limb in:

- shortened adductors: time - $6.93 \mathrm{sec}$; mistakes in the performance - 2.2 errors;

- without shortening adductors: time -6.93 sec; mistakes in the performance - 3 errors;

- not statistically significant difference in 
time $-0.00 \sec (t=.01 ; \mathrm{P}(\mathrm{t})=1 \%) ;$

- not statistically significant difference in mistakes -0.8 errors $(t=.95 ; \mathrm{P}(\mathrm{t})=74 \%$. $)$;

- not practical importance Cohen's: time $d=0.000$; mistakes $-d=.256$.

The correlation in $2 \mathrm{G}$ of the teenagers between Test for the left hip adductors and Shark Skill Test on the right lower limb is (Table 2):

- shortened adductors - $6.54 \mathrm{sec}$; mistakes in the performance - 2 errors;

- without shortening adductors - $6.95 \mathrm{sec}$; mistakes in the performance -2.3 errors;

- not statistically significant difference in time $-0.4 \sec (t=.45 ; \mathrm{P}(\mathrm{t})=34 \%)$;

- not statistically significant difference in mistakes -0.3 errors $(t=0.3 ; \mathrm{P}(\mathrm{t})=23 \%$. $)$;

- not practical importance Cohen's: time $d=.108$; mistakes $-d=.084$.

Table 3. Results of $1 G$ 's Shark skill test in norm and shortened adductors of the right lower limb

\begin{tabular}{|c|c|c|c|c|c|c|c|c|c|c|}
\hline \multirow{2}{*}{ Shark skill test } & \multicolumn{3}{|c|}{ Norm add } & \multicolumn{3}{|c|}{ Shortened add } & \multirow{2}{*}{$d$} & \multirow{2}{*}{$\begin{array}{c}\text { Cohen's } \\
\mathrm{d}\end{array}$} & \multirow{2}{*}{$\mathrm{t}$} & \multirow{2}{*}{$\mathrm{P}(\mathrm{t})$} \\
\hline & $\mathrm{n}$ & $\bar{X} 1$ & $\mathrm{~S} 1$ & $\mathrm{n}$ & $\bar{X} 2$ & $\mathrm{~S} 2$ & & & & \\
\hline Left time & 2 & 5.95 & 0.49 & 20 & 4.69 & 0.71 & 1.2 & 0.718 & 2.44 & 98 \\
\hline Left mistakes & 2 & 2 & 1.41 & 20 & 0.8 & 0.89 & 1.2 & 0.453 & 1.75 & 90 \\
\hline Right time & 2 & 6.4 & 0.85 & 20 & 4.8 & 0.78 & 1.6 & 0.700 & 2.73 & 99 \\
\hline Right mistakes & 2 & 2 & 2.83 & 20 & 1.2 & 1.01 & 0.8 & 0.181 & 0.38 & 24 \\
\hline
\end{tabular}

Note: Critical value of the t-criterion of Student for independent samples at $d=n 1+n 2-2=20$ and a $=0.05$ equals 2.09; add-adductors.

Regarding the correlation between right hip adductors and Shark Skill Test on the left lower limb in the $1 \mathrm{G}$ the results are similar to these on the left (Table 3):

- shortened adductors: time - $4.69 \mathrm{sec}$; mistakes in the performance -0.8 errors;

- without shortening adductors: time -5.95 sec; mistakes in the performance - 2 errors;

- statistically significant difference in time $-1.2(t=2.44 ; \mathrm{P}(\mathrm{t})=98 \%)$;

- statistically significant difference in mistakes $-1.2(t=1.75 ; \mathrm{P}(\mathrm{t})=90 \%)$;

- high practical importance Cohen's: time $d=.718$; mistakes $-d=.453$.
The results on right hip adductors and Shark Skill Test on the right lower limb (Table 3) are slightly different:

- shortened adductors: time $-4.8 \mathrm{sec}$; mistakes in the performance -1.2 errors;

- without shortening adductors: time -6.4 sec; mistakes in the performance -2 errors;

- statistically significant difference in time $-1.6 \sec (t=2.73 ; \mathrm{P}(\mathrm{t})=99 \%)$;

- not statistically significant difference in mistakes $-0.8(t=.38 ; \mathrm{P}(\mathrm{t})=24 \%)$;

- practical importance Cohen's: time - high $d=.700$; mistakes - low $d=.181$.

Table 4. Results of $2 G$ 's Shark skill test in norm and shortened adductors at right lower limb

\begin{tabular}{|c|c|c|c|c|c|c|c|c|c|c|}
\hline \multirow{2}{*}{ Shark skill test } & \multicolumn{3}{|c|}{ Norm add } & \multicolumn{3}{|c|}{ Shortened add } & \multirow{2}{*}{ d } & \multirow{2}{*}{$\begin{array}{c}\text { Cohen's } \\
\text { d }\end{array}$} & \multirow{2}{*}{$\mathrm{t}$} & \multirow{2}{*}{$P(t)$} \\
\hline & $\mathrm{n}$ & $\overline{\mathrm{X}} 1$ & $\mathrm{~S} 1$ & $\mathrm{n}$ & $\overline{\mathrm{X}} 2$ & $\mathrm{~S} 2$ & & & & \\
\hline Left time & 3 & 6.53 & 1.45 & 18 & 6.99 & 1.54 & 0.4 & 0.000 & 0.48 & 36 \\
\hline Left mistakes & 3 & 2.7 & 1.53 & 18 & 2.3 & 1.6 & 0.4 & 0.256 & 0.391 & 30 \\
\hline Right time & 3 & 7.5 & 2.27 & 18 & 6.5 & 1.5 & 1 & 0.108 & 1.08 & 71 \\
\hline Right mistakes & 3 & 2.3 & 2.5 & 18 & 2 & 1.33 & 0.3 & 0.084 & 0.357 & 27 \\
\hline
\end{tabular}

Note: Critical value of the t-criterion of Student for independent samples at $d=n 1+n 2-2=19$ and a $=0.05$ equals 2.09; add-adductors. 
Table 4 shows the results of the $2 \mathrm{G}$ balance test for teenagers with shortened and normal right hip adductors. The differences are minor without statistically significant and practical importance as the left one.

According to asymmetry of the adductor elasticity in both groups no statistically significant differences were found in the duration and mistakes of Shark skill test.

\section{DISCUSSION}

Overloading of basketball players' adductor muscles as a result of specific movements and jumps from semi squat positions may also result in strong abduction or adduction. Short adductors, diagnosed with Patrick's test, occur in this study in men with average 20.9 years (Table 1 and Table 3).

The literature on the assessment of the shortening of basketball players' certain muscle groups for prophylactic purposes is scarce. Liebenson (1990) points out that competitive basketball and volleyball players frequently suffer different forms of knee dysfunctions due to muscular imbalances. Their ability to jump is often severely impaired due to the presence of shortened muscles associated with weakness of other muscles.

Nevertheless, the results from the Shark Skill Test on the left and on the right lower limb demonstrated statistically significant better time and fewer mistakes among $1 \mathrm{G}$ basketball players (average 20.9 years) with shorter left and right adductors than these with normal adductors' elasticity. The athletes in $1 \mathrm{G}$ with short left adductors performed balance test on the left lower limb with $1.3 \mathrm{sec}(t=3.3 ; \mathrm{P}(\mathrm{t})=$ $100 \%)$ faster and 1.2 fewer mistakes $(t=2.30$; $\mathrm{P}(\mathrm{t})=97 \%$.). The results were similar to those in the performance of the Shark Skill Test on the right lower limb. The players in $1 \mathrm{G}$ with short left adductors were $1.6 \mathrm{sec}$ faster $(t=$ $3.71 ; \mathrm{P}(\mathrm{t})=100 \%)$ and had 1.2 fewer mistakes $(t=1.01 ; \mathrm{P}(\mathrm{t})=91 \%$.). The same data were recorded in $1 \mathrm{G}$ with the right adductors (Table 3). During performance of the Shark Skill Test on the left lower limb the time was better 1.2 $(t=2.44 ; \mathrm{P}(\mathrm{t})=98 \%)$ among the basketball players with short right adductors and $1.2(t$ $=1,75 ; \mathrm{P}(\mathrm{t})=90 \%)$ fewer mistakes. This tendency was preserved in the balance test for the right lower limb. Again, the athletes with short right adductors had 1,6 $\mathrm{sec}$ better time $(t=$ 2.73; P ( $\mathrm{t})=99 \%$ ). And only in this part there was not statistically significant difference in mistakes $-0.8(t=.38 ; \mathrm{P}(\mathrm{t})=24 \%)$

Despite the better Shark Skill test results for basketball players with shortened hip adductors, shortening should be treated as it may provoke hip and sacroiliac disorders or medial knee pain, pain in the hip joint, intrapelvis pain, and difficulty in activating gluteus medius (Liebenson, 1990).

On the other hand, the results of youth basketball players were various (Table 2 and Table 4). The differences in time and mistakes during performance of the Shark Skill Test on the left and right lower limb among athletes with and without shortness of the hip adductors were minor, not statistically significant and have less practical importance.

\section{CONCLUSION}

Summarizing the results, it is clear that the basketball play causes the shortening of the hip adductors of the men (on the left $86.36 \%$, and on the right $-90.9 \%$ ) and of the teenagers (on the left $-80.95 \%$, and on the right $-85.7 \%$ ).

In this aspect, it is important that the asymmetry of the adductor elasticity in both groups does not lead to statistically significant differences in the duration and mistakes during performance of the Shark skill test.

Regarding the results from the Shark Skill Test basketball players in $1 \mathrm{G}$ with short left 
and right adductors demonstrated statistically significant better time and fewer mistakes during performance of both lower limbs. In fact, there was a correlation between Patrick's Test and Shark Skill Test in this group.

In our opinion, it is necessary to expand the study by applying physiotherapy for the shortened hip adductors and track changes in the implementation of the Shark Skill Test before and after treatment.

This tendency is not seen among young basketball players. There are no statistically significant differences in the performance of the Shark Skill Test between athletes with and without shortening the hip adductors. This fact confirms the need for physiotherapy for timely prevention.

\section{REFERENCES}

Gatz, G. (2009). Complete conditioning for soccer. Leeds: Human Kinetics, USA, Chapter 4, pp. 24-25.

Gluck, N., Liebenson, C. (1997). Paradoxical muscle function. Journal of Bodywork and Movement Therapies, 1(4), pp. 219-222.

Damianova, R., Gigova, V. (2000). Guidance for seminars on statistical methods in sport. Second ed. NSA Press, Sofia.

Damianova, R., Gigova, V. (2002). Statistical methods in sport. Textbook, Third ed. NSA Press, Sofia.

Levit, K. (1981). Manual therapy. Medicine and Physical culture, Sofia, pp.120-126.

Liebenson, C. (1990). Active muscular relaxation techniques (part 2). Journal of $\mathrm{Ma}$ nipulative and Physiological Therapeutics, 13(1), pp. 2-6.

Corresponding author:

Rumiana Tasheva

Department of Theory and Methodics of Kinesitherapy National Sports Academy „Vassil Levski” Studentski grad, 21, Acad. Stefan Mladenov str. Sofia 1700, Bulgaria E-mail: rumiana_tasheva@yahoo.com 